\title{
Enhanced Dispersion of Graphene in Epoxy-Acrylic Waterborne Anticorrosion Coating: Bifunctional Ligands Linking Graphene to $\mathrm{SiO}_{2}$
}

Lei Guo ${ }^{l \#}$, Lingzhi Jing ${ }^{l \#}$, Yan Liu ${ }^{l}$, Bingjie Zou ${ }^{l}$, Sicheng Hua ${ }^{l}$, Jiangpeng Zhang ${ }^{l}$, Dayang Yu ${ }^{l}$, Shuchuan Wang ${ }^{2}$, Shirong Wang ${ }^{2}$, Lidong Wang ${ }^{3, *}$, Jingxia Yang ${ }^{1,2,3, *}$

1 College of Chemistry and Chemical Engineering, Shanghai University of Engineering Science, LongTeng Road 333, 201620 Shanghai, P. R. China

${ }^{2}$ T\&H chemicals CO. LTD, Tangxi Industrial Zone, Quanzhou Luojiang District, 362011, Fujian, P.R. China

${ }^{3}$ School of Materials Science and Engineering, Harbin Institute of Technology, Harbin, 150001, China

${ }^{\#}$ L. Guo and L. Jing contributed equally to this work.

*E-mail: yjx09tj@,foxmail.com, wld@hit.edu.cn

doi: $10.20964 / 2018.12 .79$

Received: 8 September 2018 / Accepted: 11 October 2018 / Published: 5 November 2018

The dispersion of graphene was improved by using a bifunctional ligand $p$-aminobenzoic acid (PABC) to anchor graphene $(\mathrm{Gr})$ to $\mathrm{SiO}_{2}$ particles (marked as $\mathrm{SiO}_{2}-\mathrm{PABC}-\mathrm{Gr}$ ). This can avoid the phase separation and improve the dispersion of graphene in coatings. The materials were characterized by Fourier transform infrared spectroscopy (FT-IR), scanning electron microscope (SEM), X-ray diffraction (XRD) and Raman spectra to prove the linking structure. An epoxy-acrylic (EA) resin was used as the binder, which contained $\mathrm{COOH}$ groups to connect with $\mathrm{SiO}_{2}$ particles. The synthesized $\mathrm{SiO}_{2}$-PABC-Gr $(1 \mathrm{wt} \%)$ was dispersed in EA resin and used as anticorrosion protection composite coating of low carbon steel, and the corrosion resistance was investigated by potentiodynamic polarization curve and electrochemical impedance spectroscopy (EIS). The results indicated that graphene was successfully linked to $\mathrm{SiO}_{2}$ by $\mathrm{PABC}$, and the application in EA resin can significantly improve the anticorrosion ability of the coating, which can be attributed to the high dispersion of graphene.

Keywords: Anticorrosion; graphene dispersion; composite; epoxy-acrylic resin; waterborne coating; bifunctional ligand 
(C) 2018 The Authors. Published by ESG (www.electrochemsci.org). This article is an open access article distributed under the terms and conditions of the Creative Commons Attribution license (http://creativecommons.org/licenses/by/4.0/). 